Disponível em:

http://editora.unoesc.edu.br/index.php/race

Race, Joaçaba, v. 14, n. 2, p. 677-706, maio/ago. 2015

\title{
UM MODELO DE AVALIAÇÃO DO RELACIONAMENTO FRANQUEADOR- FRANQUEADO COM BASE NAS LACUNAS DA QUALIDADE DO SERVIÇO: UM ESTUDO DE CASO EM UMA REDE DO SETOR FARMACÊUTICO
}

\section{A model of evaluation of the franchisor-franchisee relationship based on the gaps of the service quality: a case study in a pharmaceutical industry chain}

Marcel Lima Ribeiro Dantas

E-mail: marcellrdantas@yahoo.com.br

Mestre em Administração pela Universidade Poriguar; doutorando em Administração pela Universidade Federal do Rio Grande do Norte; Professor da Universidade Potiguar.

Endereço para contato: Avenida Roberto Freire, 2184, Capim Macio, 59082-902,

Natal, Rio Grande do Norte, Brasil.

Domingos Fernandes Campos

E-mail: domingos_campos@uol.com.br

Doutor em Engenharia da Produção pela Universidade Politécnica de Madrid; Mestre em Engenharia da Produção pela Universidade Federal de Santa Catarina; Professor do Mestrado Profissional em Administração da Universidade Potiguar.

Evádio Pereira Filho

E-mail: evadio.filho@ifrn.edu.br

Mestre em Administração pela Universidade Potiguar; Especialista em Gestão Ambiental pelo Instituto Federal de Educação, Ciência e Tecnologia do Rio Grande do

Norte; Administrador do Instituto Federal de Educação, Ciência e Tecnologia do

Rio Grande do Norte.

Alípio Ramos Veiga Neto

E-mail:alipio@veiga.net

Doutor em Psicologia pela Pontifícia Universidade Católica de Campinas; Mestre em Psicologia Educacional pela Pontifícia Universidade Católica de Campinas; Coordenador do Programa de Mestrado em Administração da Universidade Potiguar.

Artigo recebido em 20 de março de 2015. Aceito em 30 de abril de 2015. 
Resumo

O objetivo deste artigo foi apresentar um modelo de avaliação das relações franqueadorfranqueado com base no modelo das lacunas entre expectativas e percepções do serviço prestado por franqueador e franqueado e avaliar os resultados de sua aplicação a uma rede de franquias do setor Farmacêutico. Os modelos de avaliação do franchising foram descritos e analisados criticamente com o objetivo de conhecer seus elementos básicos. Com fundamento na literatura e em entrevistas com grupos focais, ajustes foram incorporados ao modelo desenvolvido para avaliar o relacionamento franqueador-franqueado. Divergências importantes foram constatadas no relacionamento de curto prazo. No entanto, franqueador e franqueados demonstraram que suas prioridades estão alinhadas nos sete atributos que compõem o relacionamento de longo prazo. O modelo das lacunas de qualidade mostrou-se adequado ao processo de avaliação do relacionamento entre franqueados e franqueador em curto e longo prazos.

Palavras-chave: Franquias. Relacionamento franqueador-franqueado. Qualidade de serviço.

\title{
A model of evaluation of the franchisor-franchisee relationship based on the gaps of the service quality: a case study in a pharmaceutical industry chain
}

\begin{abstract}
This study presents an evaluation model of franchisor-franchisee relations based on the model of the gaps between expectations and perceptions of service for franchisor and franchisee and evaluate the results of its application to a network of franchises in the Pharmaceutical industry. Evaluation models of franchising were described and critically analyzed in order to meet its basic elements. Based on literature and interviews with focus groups, adjustments were incorporated into the model developed to evaluate the franchisorfranchisee relationship. Significant differences were observed in short-term relationship. However, franchisor and franchisees showed that their priorities are aligned in the seven attributes that make up the long-term relationship. The model of quality gaps was appropriate and adherent to the evaluation of the relationship between franchisor and franchisees in the short and long term process.

Keywords: Franchising. Franchisor-franchisee relationship. Service quality.
\end{abstract}

\section{INTRODUÇÃO}

As redes de franquias se expandem rapidamente em países desenvolvidos como Estados Unidos e França, além de nações em desenvolvimento como Brasil, China e Filipinas (PERRIGOT, 2006). No período entre 2003 e 2014, o faturamento do sistema de franquias no Brasil passou de 29,044 para 127,331 bilhões de reais, havendo um incremento anual que variou entre 7,7\% e 20,4\%. Nesse mesmo período, o número de unidades franqueadas saltou de 56.564 para 125.641, 
enquanto o número de redes, de 678 para 2.942 (ASSOCIAÇÃO BRASILEIRA DE FRANCHISING, 2015). A importância do franchising no Brasil também está ligada à criação e à sobrevivência de micro e pequenas empresas (ESPINHA; MACHADO; RODRIGUES, 2005). Na maioria das economias, o setor privado é formado por pequenas empresas, entretanto, quase um terço dessas empresas não sobrevive ao primeiro ano e pouco menos da metade não resiste aos três primeiros anos (ABDULLAH et al., 2008).

O franchising vem ganhando destaque e atraindo interesse de pesquisadores que buscam entender suas implicações econômicas e estratégicas (DAVIDOVITSCH; CALDAS; SILVA, 2009). Melo e Andreassi (2010) investigaram as publicações nacional e internacional sobre o franchising no período de 1998 a 2007. Por meio de uma meta-análise, encontraram 24 publicações nacionais. Nenhuma delas abordou o relacionamento franqueador-franqueado como tema principal. Foram identificados 37 artigos, em 15 periódicos internacionais, entre eles, dois trabalhos $(5,4 \%)$ trataram do relacionamento. Por sua vez, Brito, Vieira e Espartel (2011) realizaram uma análise sobre a produção científica no varejo e apontaram alguns "esquecimentos acadêmicos" em periódicos nacionais e internacionais. Esses pesquisadores assinalaram temáticas no varejo que possuem significativo potencial para novas pesquisas, como franchising, imagem da marca, estratégias de serviços, compras coletivas, mídias sociais e relacionamento no canal (B2B).

Grunhagen e Dorsch (2003 apud Vance, Fávero, Luppe, 2008) ressaltam que há uma perspectiva de longo prazo envolvida no relacionamento. Expectativas conflitantes entre franqueador e franqueado são responsáveis pelo fracasso de alguns empreendimentos, o que aponta a necessidade de investigar o relacionamento entre franqueador e franqueado (COHEN; SILVA, 2000). Há modelos que facilitam a compreensão desse tipo de relacionamento de maneira global ou de elementos que o compõem. Cada modelo possui suas contribuições e limitações. Podem ser citados: Dant, Li e Wortzel (1995), Cohen e Silva (2000), Monroy e Alzola (2005), Vieira e Slongo (2006), Bordonaba-Juste e Polo-Redondo (2008), Dickey, Mcknight e George (2008), Davies et al. (2011), McDonell, Beatson e Huang (2011) e Wright e Grace (2011).

No relacionamento franqueador-franqueado são geradas expectativas mútuas para a prestação de serviços de cada uma das partes (ROCHA, 2010). Essas lacunas a rigor podem ser apreciadas segundo o modelo de (des)confirmação entre o que o cliente espera e o serviço prestado, como concebido por Gronross (2009) e pela modelagem idealizada por Parasuraman, Zeithaml e Berry (2006), para os quais 
a qualidade do serviço resulta da comparação entre a expectativa e a percepção do serviço recebido. Com base na teoria de gestão dos serviços, é possível apreender as expectativas de franqueador e franqueados, bem como as lacunas e o nível de satisfação das partes envolvidas em curto e longo prazos.

Assim, a questão central que aqui se coloca é como identificar e avaliar o relacionamento entre franqueador e franqueados, utilizando-se as dimensões e os atributos concernentes aos diversos aspectos da gestão das franquias e incorporando as expectativas e percepções sobre o serviço prestado pelas partes, seja nas relações transitórias de curto prazo seja nas relações permanentes de prazo mais longo.

Este artigo teve como objetivo apresentar um modelo de avaliação das relações franqueador-franqueado com base no modelo das lacunas entre expectativas e percepções do serviço prestado por franqueador e franqueado e avaliar os resultados de sua aplicação a uma rede de franquias de farmácias de manipulação.

\section{REFERENCIAL TEÓRICO}

As franquias são classificadas em diversas gerações, conforme o apoio e as garantias oferecidas pelo franqueador. As franquias de primeira e segunda gerações são chamadas de franquias de marca e produto, uma vez que incluem apenas a concessão de direitos do uso da marca e de comercialização de produtos. As franquias de terceira geração são chamadas de franquias de formato de negócio. Nas franquias dessa geração, o apoio oferecido pelo franqueador ao franqueado é mais vasto e abrange a transferência de conhecimento de todo o modelo de gerenciamento do negócio (SILVA; AZEVEDO, 2012). O Quadro 1 representa o relacionamento entre franqueador e franqueado em uma franquia de terceira geração.

Quadro 1 - Características dos sistemas de franquias

\begin{tabular}{|l|l|}
\hline \multicolumn{2}{|c|}{ Contrato de franquia } \\
\hline FRANQUEADOR & FRANQUEADO \\
\hline É proprietário da marca & Utiliza a marca \\
$\begin{array}{l}\text { Oferece assistência: } \\
\text { (algumas vezes) financiamento } \\
\text { propaganda e marketing } \\
\text { treinamento }\end{array}$ & Expande o negócio com o apoio do \\
\hline Recebe taxas & \\
\hline
\end{tabular}

Fonte: Beshel (2001 apud SILVA; AZEVEDO, 2012). 
Há ainda as franquias de geração superior (SILVA; AZEVEDO, 2012). Nas franquias de terceira geração e de geração superior, cresce a importância do relacionamento entre franqueador e franqueado. No momento em que estes firmam um contrato de franquia, são geradas expectativas para a prestação de serviço entre as partes (ROCHA, 2010). O franqueador possui expectativas quanto ao franqueado, sobretudo acerca do faturamento e das normas de operação da unidade franqueada (PRADO 2008, apud MAEMURA, 2009).

As relações ocorrem de forma que o franqueador presta serviços ao franqueado, como treinamentos, assistências técnica e comercial contínuas, entre outros serviços e, por isto, recebe uma soma monetária fixa (taxa de franquia) e parcelas das vendas das unidades franqueadas sob a forma, por exemplo, de royalties e/ou taxa de publicidade (SILVA; AZEVEDO, 2007). Um dos fatores críticos na relação franqueador-franqueado é a satisfação do franqueado com o serviço prestado pelo franqueador, visto que a insatisfação pode resultar no rompimento do contrato de franquia.

O relacionamento franqueador-franqueado agrega duas áreas distintas: transacional (curto prazo) e relacional (longo prazo). Assim, a qualidade do relacionamento de curto prazo se concentra em fatores determinantes para o sucesso na abertura da franquia. Dado o envolvimento na implantação da franquia, a qualidade do relacionamento de curto prazo pode ser avaliada na perspectiva do franqueado e na do franqueador. Dessa forma, a perspectiva do fraqueado avalia o serviço prestado pelo franqueador, enquanto a do franqueador mede o serviço oferecido pelo franqueado. A qualidade vai além das transações e origina relacionamento de longo prazo, agregando variáveis como confiança e compromisso (MONROY; ALZOLA, 2005).

\section{1 MODELOS PARA A AVALIAÇÃO DO RELACIONAMENTO FRANQUEADOR-FRANQUEADO}

Os modelos para a avaliação do relacionamento franqueador-franqueado apresentados neste artigo foram utilizados nos Estados Unidos, Brasil, Espanha, Taiwan, Austrália e Nova Zelândia. Alguns se limitam, no trabalho original, ao campo teórico: Dant, Li e Wortzel (1995), Vieira e Slongo (2006) e Monroy e Alzola (2005). Os demais foram concebidos e testados em segmentos como fast-food, prestação de serviços, lavanderia e perfumaria. Parte destes modelos aborda a relação global entre 
franqueador e franqueado: Dant, Li e Wortzel (1995), Cohen e Silva (2000), Vieira e Slongo (2006) e Monroy e Alzola (2005). Originalmente, a modelagem desenvolvida por Monroy e Alzola (2005) teve o propósito de investigar a gestão da qualidade em sistemas de franquia, enquanto a concebida por Vieira e Slongo (2006) teve como temática central o marketing de relacionamento entre franqueador e franqueado, porém, ambas podem ser utilizadas para medir o relacionamento destes.

Os demais modelos, Bordonaba-Juste e Polo-Redondo (2008), Dickey, Mcknight e George (2008), Davies et al. (2011), McDonell, Beatson e Huang (2011) e Wright e Grace (2011) tratam de aspectos do relacionamento de longo prazo. Monroy e Alzola (2005) subdividem confiança em dois componentes distintos: confiança na credibilidade e confiança na benevolência. Para Cohen e Silva (2000), a confiança do franqueado no seu franqueador está ligada ao cumprimento do contrato e de promessas informais, além de valores éticos e transparência nos negócios. Por sua vez, o compromisso é descrito como esforço para garantir a continuidade da parceria, evitar conflitos e resolver problemas. Por fim, Dickey, Mcknight e George (2008) medem a confiança por meio de dois itens, confiança na credibilidade e confiança na honestidade.

O Quadro 2 exibe um conjunto de modelos para a avaliação do relacionamento franqueador-franqueado e suas respectivas dimensões.

Quadro 2 - Dimensões presentes nas modelagens sobre o relacionamento franqueador-franqueado

\begin{tabular}{|l|l|l|l|}
\hline Autor & Ano & País & Dimensões \\
\hline $\begin{array}{l}\text { Dant, Li } \\
\text { e Wortzel }\end{array}$ & 1995 & $\begin{array}{l}\text { Estados } \\
\text { Unidos }\end{array}$ & $\begin{array}{l}\text { Consciência, clareza e cobertura do contrato; } \\
\text { enfoque relacional; troca de informações; mu- } \\
\text { tualidade; flexibilidade; cooperação; estratégias } \\
\text { de influência; decisão participativa; resolução de } \\
\text { conflitos; competências }\end{array}$ \\
\hline Cohen e Silva & 2000 & Brasil & $\begin{array}{l}\text { Transferência de know-how; suporte administrativo } \\
\text { operacional; comunicação; confiança; compro- } \\
\text { misso }\end{array}$ \\
\hline $\begin{array}{l}\text { Mlzola } \\
\text { Alzoy e }\end{array}$ & 2005 & Espanha & $\begin{array}{l}\text { Desenvolvimento do negócio; cumprimento do } \\
\text { treinamento; realização do pagamento; uniformi- } \\
\text { dade; transparência; treinamento; apoio; infor- } \\
\text { mação; suprimento; facilidade no financiamento; } \\
\text { assistência gerencial; acesso; confiança, compro- } \\
\text { misso; normas sociais de relacionamento }\end{array}$ \\
\hline
\end{tabular}




\begin{tabular}{|c|c|c|c|}
\hline $\begin{array}{l}\text { Vieira e } \\
\text { Slongo }\end{array}$ & 2006 & Brasil & $\begin{array}{l}\text { Suporte contínuo; financeiro; performance de } \\
\text { marketing; clima; conflito; compromisso; comuni- } \\
\text { cação; cooperação }\end{array}$ \\
\hline $\begin{array}{l}\text { Bordona- } \\
\text { ba-Juste e Po- } \\
\text { lo-Redondo }\end{array}$ & 2008 & Espanha & $\begin{array}{l}\text { Troca de informações e comportamentos de coo- } \\
\text { peração; confiança; compromisso; satisfação }\end{array}$ \\
\hline $\begin{array}{l}\text { Dickey, Mck- } \\
\text { night } \\
\text { e George }\end{array}$ & 2008 & $\begin{array}{l}\text { Estados } \\
\text { Unidos }\end{array}$ & $\begin{array}{l}\text { Confiança na competência do franqueador; con- } \\
\text { fiança na honestidade do franqueador; autonomia; } \\
\text { identificação; observância; qualidade do relaciona- } \\
\text { mento; satisfação; compromisso }\end{array}$ \\
\hline Davies et al. & 2011 & $\begin{array}{l}\text { Estados } \\
\text { Unidos }\end{array}$ & $\begin{array}{l}\text { Confiança; satisfação; conflito; cumprimento das } \\
\text { normas do franqueador }\end{array}$ \\
\hline $\begin{array}{l}\text { McDonell, } \\
\text { Beatson e } \\
\text { Huang }\end{array}$ & 2011 & Taiwan & $\begin{array}{l}\text { Lealdade do franqueado; confiança; compromisso; } \\
\text { satisfação; cooperação }\end{array}$ \\
\hline $\begin{array}{l}\text { Wright e } \\
\text { Grace }\end{array}$ & 2011 & Austrália & $\begin{array}{l}\text { Confiança; compromisso; congruência de metas; } \\
\text { cultura organizacional; comunicação }\end{array}$ \\
\hline
\end{tabular}

Fonte: os autores.

Em trabalhos na Língua Portuguesa, destaca-se a utilização da modelagem desenvolvida por Cohen e Silva (2000) utilizada por outros pesquisadores como Paiva (2009), Rocha (2010) e Dantas et al. (2012). Essa modelagem avalia o relacionamento franqueador-franqueado por meio de cinco dimensões observáveis, porém, não afere separadamente os atributos que compõem as dimensões.

Monroy e Alzola (2005) e Bordonaba-Juste e Polo-Redondo (2008) distinguem o relacionamento franqueador-franqueado segundo a projeção de curto longo prazos. Porém, apenas os primeiros avaliam separadamente a perspectiva de franqueador e franqueado na projeção de curto prazo. Essa projeção é voltada para a implantação da franquia, enquanto a projeção de longo prazo se inicia quando as empresas vão além da troca baseada em transações (MONROY; ALZOLA, 2005).

\section{2 MODELO DE QUALIDADE DO SERVIÇO}

Clientes avaliam a qualidade de um serviço baseados em um padrão interno anterior à experiência de serviço, ou seja, em razão de suas expectativas (LOVELOCK; WRIGHT, 2006). O serviço esperado é influenciado pela experiência anterior, necessidades pessoais dos clientes, comunicação boca a boca e comunicação de mercado da empresa (GRONROSS, 2009). O grau de satisfação do cliente decorre de uma comparação entre a expectativa e a percepção da experiência 
do serviço (CORRÊA; CAON, 2002). O desempenho do serviço além dos níveis esperados surpreende e encanta os clientes. Porém, se a qualidade cai abaixo do nível de serviços esperado pelos clientes, ocorre uma discrepância - ou lacuna de qualidade entre o desempenho do fornecedor do serviço e as expectativas do cliente (LOVELOCK; WRIGHT, 2006).

Para desenvolver modelos de gestão de serviços é preciso saber o que os clientes querem e o que avaliam das empresas de serviços (Gronross, 2009). O autor desenvolveu um modelo na qual o cliente compara o serviço esperado (expectativa) ao serviço percebido (desempenho). A qualidade percebida de um serviço é o resultado de uma avaliação em que o cliente compara suas expectativas com o serviço que recebeu. As promessas podem exercer efeitos sobre a expectativa do cliente, isso se aplica à comunicação boca a boca e à experiência anterior com o serviço.

Na mesma linha de pensamento de Gronross (2009), Parasuraman, Zeithaml e Berry (1985), com base em estudos empíricos, desenvolveram uma base conceitual sólida para a compreensão da qualidade dos serviços. Propuseram, com referência no paradigma da desconfirmação, o modelo das lacunas de qualidade. Cada lacuna (gap) representa um empecilho para a oferta de um serviço que os consumidores percebam como de qualidade elevada. Os autores encontraram lacunas importantes:

a) nas percepções da administração a respeito das expectativas dos clientes;

b) na tradução e especificação dessas expectativas por parte dos gestores - os padrões internos de desempenho fixados pela organização não refletem minuciosamente as expectativas dos clientes;

c) na realização do serviço em si pela área operacional - representa a dissonância entre desempenho real e desempenho padrão preestabelecido pela empresa;

d) na dissonância entre o serviço realizado e o que é comunicado ao cliente por informações e promessas externas sobre o ele;

e) na diferença entre as expectativas dos clientes em relação ao serviço e à percepção destes quanto ao desempenho do serviço oferecido.

No modelo das lacunas, a qualidade do serviço é medida pela diferença entre o nível de expectativas e o desempenho percebido pelos clientes. O grau 
de qualidade de um serviço é medido pela dimensão da lacuna 5 (BOWERSOX; CLOSS; COOPER, 2006; PARASURAMAN; ZEITHAML; BERRY, 1985).

\section{METODOLOGIA}

A primeira etapa desta pesquisa desenvolveu o referencial teórico baseado na gestão de serviços e no relacionamento franqueador-franqueado. Nesse passo, foi possível identificar modelos de avaliação do relacionamento franqueadorfranqueado e selecionar o mais adequado para servir como base. Sequencialmente, foram analisados os modelos voltados para avaliar o relacionamento franqueadorfranqueado e a compatibilidade de cada um deles com a teoria da gestão dos serviços associados ao relacionamento. Os modelos de avaliação do franchising foram descritos e analisados criticamente, com o objetivo de conhecer seus elementos básicos. Ao final, incorporaram-se os elementos para a apreensão de expectativas e percepções das partes sobre o serviço recebido.

Com base na literatura e em entrevistas com grupos focais, ajustes foram incorporados ao modelo desenvolvido para avaliar o relacionamento franqueadorfranqueado. O modelo completou-se com a construção do instrumento de coleta dos dados para a avaliação das lacunas de percepção do relacionamento franqueadorfranqueado. O instrumento de coleta de dados é constituído por um questionário com 12 módulos que contemplam uma avaliação quantitativa das expectativas e percepções de desempenho de franqueador e franqueados em curto e longo prazos. $\mathrm{O}$ instrumento foi aplicado na avaliação de uma rede de franquias do segmento de farmácias de manipulação. A seguir, apresenta-se o Esquema metodológico utilizado na pesquisa. 
Marcel Lima Ribeiro Dantas et al.

Esquema 1 - Metodológico

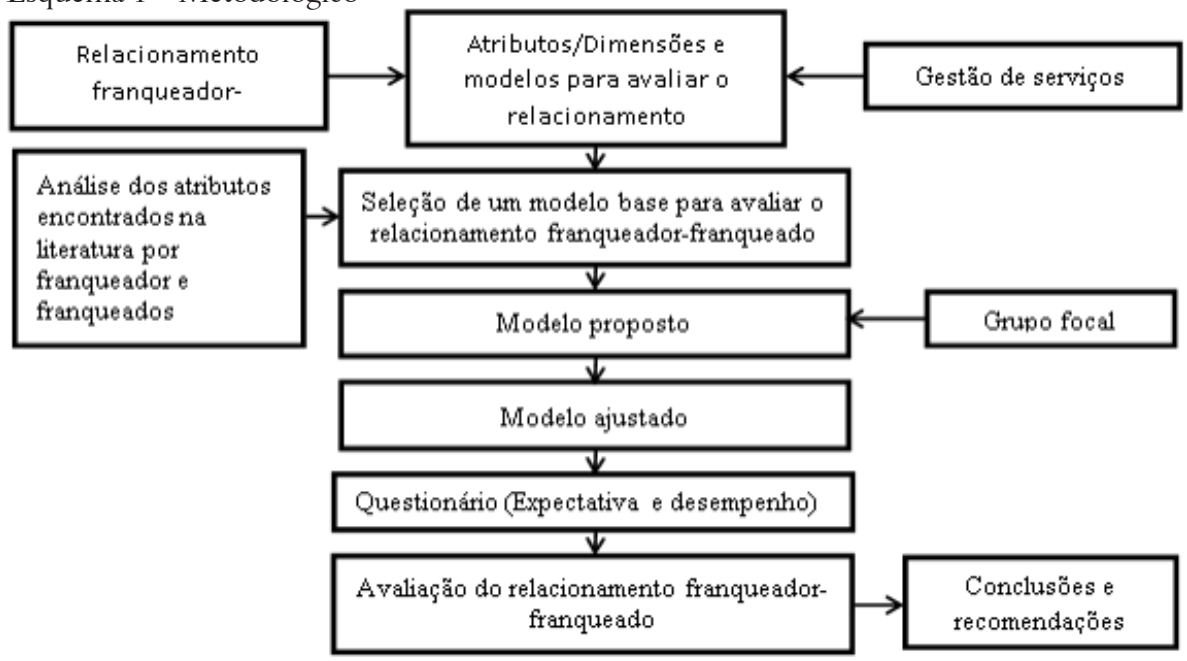

Fonte: os autores.

\section{1 O MODELO PROPOSTO}

O modelo Monroy e Alzola (2005), exposto no Quadro 3, por avaliar o relacionamento franqueador-franqueado de forma plena, incluindo perspectivas de curto e longo prazos, apresenta-se como a base a ser usada para a avaliação do relacionamento franqueador-franqueado utilizando a teoria de serviços.

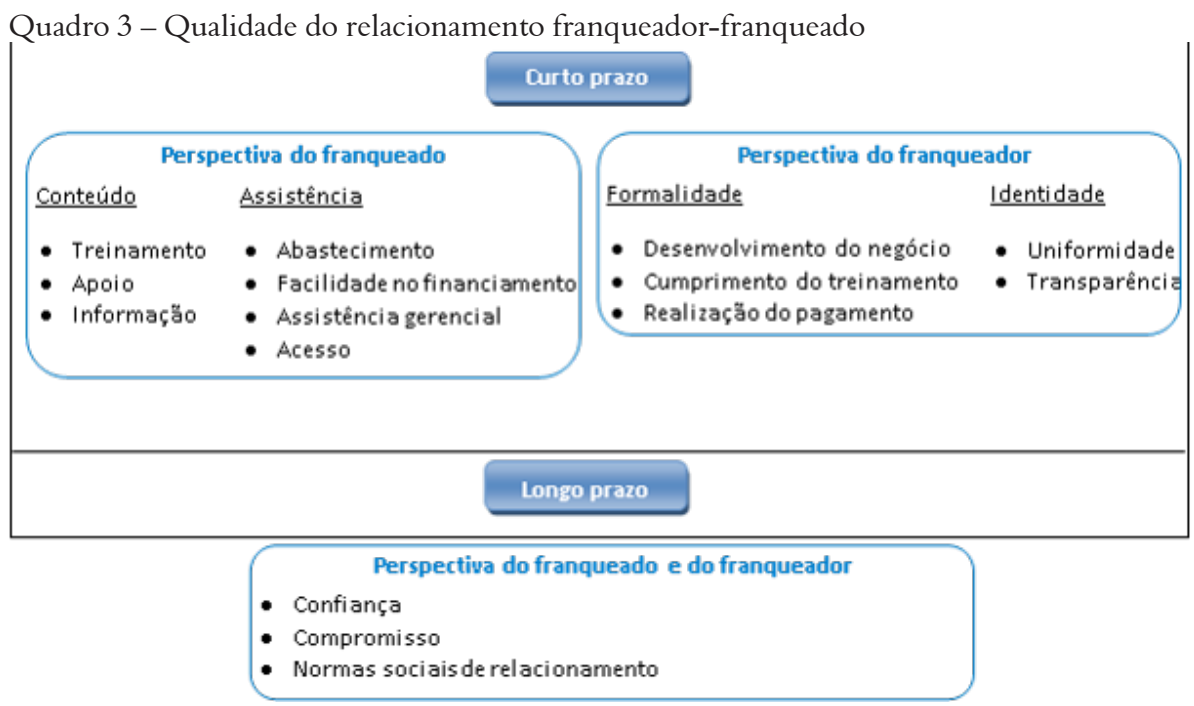

Fonte: Adaptado de Monroy e Alzola (2005). 
Monroy e Alzola (2005) não estabeleceram os atributos a serem pesquisados em cada uma das dimensões. Para a elaboração do modelo proposto, foram selecionados na literatura atributos que pudessem explicar as dimensões do modelo base. O processo de escolha dos atributos está descrito na seção imediatamente vindoura.

\section{2 ATRIBUTOS SELECIONADOS}

O modelo proposto foi apresentado para franqueador e franqueados de uma rede do setor farmacêutico, por meio de entrevistas com grupos focais em ocasiões distintas. Entrevistas desse gênero são usadas para se obterem informações em profundidade sobre problemas de serviços e podem ser utilizadas para encontrar critérios (atributos) empregados para avaliar a qualidade do serviço (LOVELOCK; WRIGHT, 2006). O pré-teste contou com a colaboração de cinco franqueados os quais avaliaram os módulos da perspectiva do franqueado da primeira versão do questionário. Ademais, os representantes do franqueador avaliaram os módulos do questionário sobre a perspectiva do franqueador. O questionário foi revisto a fim de contemplar as observações pertinentes sugeridas por representantes dos franqueados e do franqueador. Posteriormente, o questionário foi reapresentado aos mesmos colaboradores em uma nova entrevista com grupos focais. Todos os representantes aprovaram o questionário sem novas recomendações de melhorias.

Neste estudo, os termos franqueador e franqueado se referem sempre às pessoas jurídicas, portanto, avalia-se a relação entre as empresas, e não a relação entre as pessoas que representam essas organizações. Nas entrevistas com o grupo do franqueador estavam presentes o diretor geral e o diretor administrativo da franqueadora. Esse grupo auxiliou na investigação de atributos na perspectiva do franqueador, ou seja, acerca do que o franqueador espera de seus franqueados. No grupo dos franqueados, investigou-se o que os presentes esperam de seu franqueador. Esse modelo, contendo um quadro referencial com definições de todos os atributos, foi apresentado separadamente aos grupos do franqueador e dos franqueados, para que fizessem novos apontamentos. Os pesquisadores tomaram o cuidado de não restringir o modelo apenas à rede de franquia na qual foram realizadas as entrevistas com grupos focais. As dimensões e os atributos utilizados pelo modelo ajustado são apresentados nos Quadros 4, 5 e 6. 
Quadro 4 - Perspectiva do franqueado: dimensões e atributos no relacionamento de curto prazo

\begin{tabular}{|c|c|}
\hline Dimensão & Atributos \\
\hline \multirow{5}{*}{ Treinamento } & Treinamento quanto ao atendimento ao cliente \\
\hline & Treinamento quanto à administração financeira \\
\hline & Treinamento quanto à administração de recursos humanos \\
\hline & Treinamento quanto à gestão de operações \\
\hline & Treinamento quanto ao marketing \\
\hline \multirow{5}{*}{ Apoio } & $\begin{array}{l}\text { Análise da viabilidade da implantação da franquia (análise da viabilida- } \\
\text { de do projeto) }\end{array}$ \\
\hline & Escolha do ponto comercial \\
\hline & Planejamento do layout da unidade franqueada \\
\hline & Assistência na compra de equipamentos \\
\hline & Assistência na inauguração \\
\hline Informação & $\begin{array}{l}\text { Clareza e completude das cláusulas do contrato de franquia empresa- } \\
\text { rial }\end{array}$ \\
\hline \multirow{3}{*}{ Abastecimento } & Adquiridos pelo franqueado do franqueador \\
\hline & $\begin{array}{l}\text { Adquiridos pelo franqueado de fornecedores, com a mediação do } \\
\text { franqueador }\end{array}$ \\
\hline & Adquiridos pelo franqueado diretamente de fornecedores licenciados \\
\hline Financiamento & $\begin{array}{l}\text { Parcerias entre franqueador e bancos que facilitem financiamento ao } \\
\text { franqueado }\end{array}$ \\
\hline \multirow{4}{*}{$\begin{array}{l}\text { Assistência } \\
\text { permanente }\end{array}$} & Consultoria de campo (suporte técnico ou assistência técnica) \\
\hline & Manual de operações \\
\hline & Assistência em propaganda \\
\hline & Fornecimento/desenvolvimento de material promocional \\
\hline Acesso & Facilidade no contato entre franqueado e franqueador \\
\hline
\end{tabular}

Fonte: os autores.

Quadro 5 - Perspectiva do franqueador: dimensões e atributos no relacionamento de curto prazo

\begin{tabular}{|c|c|}
\hline Dimensão & Atributos \\
\hline $\begin{array}{l}\text { Desenvolvimento } \\
\text { do negócio }\end{array}$ & Cumprimento da missão organizacional pelo franqueado \\
\hline \multirow{5}{*}{$\begin{array}{l}\text { Cumprimento do } \\
\text { treinamento }\end{array}$} & Cumprimento do treinamento quanto ao atendimento ao cliente \\
\hline & Cumprimento do treinamento quanto à administração financeira \\
\hline & $\begin{array}{l}\text { Cumprimento do treinamento quanto à administração de recursos } \\
\text { humanos }\end{array}$ \\
\hline & Cumprimento treinamento quanto à gestão de operações \\
\hline & Cumprimento do treinamento quanto ao marketing \\
\hline \multirow{2}{*}{$\begin{array}{l}\text { Realização do pa- } \\
\text { gamento e taxas }\end{array}$} & Pagamento da taxa de franquia \\
\hline & Pagamento da taxa de royalties \\
\hline \multirow{3}{*}{ Uniformidade } & Respeito à identidade visual da franquia \\
\hline & Atuação apenas em território acordado em contrato \\
\hline & Oferta apenas de produtos e serviços autorizados pelo franqueador \\
\hline Transparência & Auditoria de campo realizada pelo franqueador na unidade franqueada \\
\hline
\end{tabular}

Fonte: os autores. 
Quadro 6 - Perspectiva franqueador-franqueado: dimensões e atributos no relacionamento de curto prazo

\begin{tabular}{|l|l|}
\hline Dimensão & Atributos \\
\hline \multirow{2}{*}{ Confiança } & Competência \\
\cline { 2 - 2 } & Honestidade \\
\hline Compromisso & Compromisso \\
\hline \multirow{4}{*}{$\begin{array}{l}\text { Normas sociais de } \\
\text { relacionamento }\end{array}$} & Solidariedade \\
\cline { 2 - 2 } & Mutualidade \\
\cline { 2 - 2 } & Flexibilidade \\
\cline { 2 - 2 } & Harmonização de conflitos \\
\hline
\end{tabular}

Fonte: os autores.

\section{3 INSTRUMENTO DE COLETA}

A partir do modelo ajustado, desenvolveu-se um questionário para avaliar a percepção de franqueador e franqueado sobre a importância e o desempenho de um conjunto de atributos. O instrumento de coleta de dados, questionário, é composto por 12 módulos numerados de I a XII. O Quadro 7 Tabela 1 mostra as referências de cada módulo, incluindo a perspectiva e o prazo da avaliação, quem, o que avalia e o conteúdo.

Quadro 7 - Referências de cada módulo do instrumento de coleta do modelo ajustado

\begin{tabular}{l|l|l|l|l|l}
\hline Módulo & Perspectiva & Prazo & Quem avalia & O que avalia & Conteúdo \\
\hline I & Franqueado & Curto & Franqueado & $\begin{array}{l}\text { Expectativa para o } \\
\text { franqueado }\end{array}$ & $\begin{array}{l}\text { Atributos do } \\
\text { Quadro 2 }\end{array}$ \\
\hline II & Franqueado & Curto & Franqueado & $\begin{array}{l}\text { Desempenho do } \\
\text { franqueador }\end{array}$ & $\begin{array}{l}\text { Atributos do } \\
\text { Quadro 2 }\end{array}$ \\
\hline III & Ambos & Longo & Franqueado & $\begin{array}{l}\text { Expectativa para o } \\
\text { franqueado }\end{array}$ & $\begin{array}{l}\text { Atributos do } \\
\text { Quadro 4 }\end{array}$ \\
\hline IV & Ambos & Longo & Franqueado & $\begin{array}{l}\text { Desempenho do } \\
\text { franqueador }\end{array}$ & $\begin{array}{l}\text { Atributos do } \\
\text { Quadro 4 }\end{array}$ \\
\hline V & Franqueador & Curto & Franqueado & $\begin{array}{l}\text { Expectativa para o } \\
\text { franqueador }\end{array}$ & $\begin{array}{l}\text { Atributos do } \\
\text { Quadro 3 }\end{array}$ \\
\hline VI & Franqueador & Curto & Franqueado & $\begin{array}{l}\text { Desempenho } \\
\text { autoavaliação }\end{array}$ & $\begin{array}{l}\text { Atributos do } \\
\text { Quadro 3 }\end{array}$ \\
\hline VII & Franqueado & Curto & Franqueador & $\begin{array}{l}\text { Expectativa para } \\
\text { franqueado }\end{array}$ & $\begin{array}{l}\text { Atributos do } \\
\text { Quadro 2 }\end{array}$ \\
\hline VIII & Franqueado & Curto & Franqueador & $\begin{array}{l}\text { Desempenho } \\
\text { autoavaliação }\end{array}$ & $\begin{array}{l}\text { Atributos do } \\
\text { Quadro 2 }\end{array}$ \\
\hline IX & Ambos & Longo & Franqueador & $\begin{array}{l}\text { Expectativa para o } \\
\text { franqueador }\end{array}$ & $\begin{array}{l}\text { Atributos do } \\
\text { Quadro 4 }\end{array}$ \\
\hline
\end{tabular}




\begin{tabular}{l|l|l|l|l|l}
\hline $\mathrm{X}$ & Ambos & Longo & Franqueador & $\begin{array}{l}\text { Desempenho do } \\
\text { franqueado }\end{array}$ & $\begin{array}{l}\text { Atributos do } \\
\text { Quadro 4 }\end{array}$ \\
\hline XI & Franqueador & Curto & Franqueador & $\begin{array}{l}\text { Expectativa para o } \\
\text { franqueador }\end{array}$ & $\begin{array}{l}\text { Atributos do } \\
\text { Quadro 3 }\end{array}$ \\
\hline XII & Franqueador & Curto & Franqueador & $\begin{array}{l}\text { Desempenho do } \\
\text { franqueado }\end{array}$ & $\begin{array}{l}\text { Atributos do } \\
\text { Quadro 3 }\end{array}$ \\
\hline
\end{tabular}

Fonte: os autores.

Os módulos I, II, III e IV permitem avaliar a lacuna 5 do modelo da qualidade do serviço sob a ótica dos franqueados. Os módulos I e II apreendem, respectivamente, as expectativas dos franqueados e o desempenho do serviço oferecido pelo franqueador em curto prazo. Os módulos III e IV apreendem, respectivamente, as expectativas dos franqueados e o desempenho do serviço oferecido pelo franqueador em longo prazo.

Os módulos IX, X, XI e XII permitem avaliar a lacuna 5 do modelo da qualidade do serviço sob a ótica do franqueador. Os módulos IX e X apreendem, respectivamente, as expectativas do franqueador e o desempenho do serviço oferecido pelos franqueados em longo prazo. Os módulos XI e XII apreendem, respectivamente, as expectativas do franqueador e o desempenho do serviço oferecido pelos franqueados em curto prazo.

A diferença entre expectativas apreendidas pelos módulos I e VII mostra a lacuna 1 do modelo da qualidade do serviço. Ela indica o que o franqueador pensa sobre o que esperam os franqueados em curto prazo. Mutatis mutandis, a diferença entre expectativas apreendidas pelos módulos V e IX refletem a lacuna 1. Ela indica o que os franqueados pensam sobre o que espera o franqueador em curto prazo.

A lacuna 1 também pode ser obtida em longo prazo. Como os atributos avaliados são os mesmos para franqueador e franqueados, ela pode ser obtida pela diferença entre as expectativas colhidas pelos módulos III e IX.

Os módulos VI e VIII refletem autoavaliações realizadas, respectivamente, pelos franqueados e pelo franqueador. As diferenças entre os resultados dos módulos VI-XII e VIII-II mostram lacunas de percepção do desempenho em curto prazo. As diferenças mostram o quão distante o desempenho de cada um, franqueador e franqueado, está em relação ao outro. 


\section{4 A ESCALA DE AVALIAÇÃO}

Em todos os módulos, as questões são avaliadas sobre uma escala de 11 pontos, variando de 0 a 10. As expectativas são avaliadas pelo grau de importância que cada respondente confere ao atributo (ZEITHAML; BITNER, 2003). Assim, 0 representa que o atributo não é importante e 10, que o atributo é muito importante. $\mathrm{Na}$ avaliação do desempenho, a escala também varia de 0 (péssimo desempenho) a 10 (excelente desempenho).

\section{RESULTADOS}

O modelo proposto foi aplicado em uma rede de franquias do setor Farmacêutico, visto que a sede do franqueador se localiza no Nordeste do Brasil. A rede de franquias opera também nas regiões Norte, Centro-Oeste e Sudeste. O franqueador atua no comércio varejista, especificamente no segmento de farmácias de manipulação, há 30 anos e utiliza o franchising há 17 anos. O sistema de franquia dessa rede consiste, essencialmente, no direito de utilização da marca e na transferência de tecnologia para o franqueado. Os questionários foram enviados e retornados em março de 2013. Todos os questionários remetidos foram respondidos. Cada franqueado com franquia(s) em funcionamento há pelo menos seis meses, independentemente do número de unidades franqueadas sob o seu controle, respondeu a um questionário. Esses franqueados são responsáveis por 47 unidades franqueadas da rede. Os demais franqueados não foram pesquisados, uma vez que o relacionamento de longo prazo com o franqueador poderia não estar consolidado. Por sua vez, os representantes do franqueador, Presidente e Diretor Administrativo, responderam em conjunto somente a um questionário.

Os resultados são apresentados conforme as projeções (curto e longo prazos) e perspectivas (franqueador e franqueado) do modelo ajustado. Em cada uma dessas subdivisões do relacionamento são expostas as percepções de franqueador e franqueado. Importante destacar que as percepções sobre expectativa (importância) e desempenho do franqueado foram obtidas as partir de médias aritméticas simples calculadas com base nos 25 questionários respondidos pelos franqueados. 


\section{1 PERSPECTIVA DO FRANQUEADO DO RELACIONAMENTO DE CURTO PRAZO}

A Tabela 1 apresenta as percepções do franqueado e do franqueador sobre os 20 atributos da perspectiva do franqueado do relacionamento de curto prazo. Para cada um dos envolvidos no relacionamento, estão expostos expectativa (E) e ranking $(\mathrm{R})$, em que o primeiro é o atributo mais importante e o último, o menos importante; desempenho (D) e lacuna da qualidade (L) avaliada a partir da diferença entre desempenho e expectativa.

Tabela 1 - Percepções do franqueado e do franqueador da perspectiva do franqueado em curto prazo.

(continua)

\begin{tabular}{|c|c|c|c|c|c|c|c|c|}
\hline \multicolumn{9}{|c|}{ Perspectiva do franqueado do relacionamento de curto prazo prazoprazo } \\
\hline \multirow[t]{2}{*}{ Atributo } & \multicolumn{4}{|c|}{$\begin{array}{l}\text { Avaliação pelo Franqueado- } \\
\text { FFrFFrfranqueado }^{\star}\end{array}$} & \multicolumn{4}{|c|}{$\begin{array}{l}\text { Avaliação pelo Franqueador } \\
\text { Frafranqueador }^{\star \star}\end{array}$} \\
\hline & $\mathrm{E}$ & $\mathrm{R}$ & $\mathrm{D}$ & $\mathrm{L}^{\star}$ & $\mathrm{E}$ & $\mathrm{R}$ & $\mathrm{D}$ & $L^{\star \star}$ \\
\hline Acesso ao franqueador & 9,88 & 1 & 9,52 & $-0,36$ & 10,00 & 3 & 10,00 & 0,00 \\
\hline Consultoria de campo & 9,64 & 2 & 9,08 & $-0,56$ & 10,00 & 2 & 10,00 & 0,00 \\
\hline Manual de operações & 9,56 & 3 & 9,32 & $-0,24$ & 8,00 & 14 & 9,00 & 1,00 \\
\hline Análise da viabilidade & 9,52 & 4 & 7,44 & $-2,08$ & 10,00 & 4 & 10,00 & 0,00 \\
\hline $\begin{array}{l}\text { Abastecimento no fran- } \\
\text { queador }\end{array}$ & 9,52 & 5 & 8,32 & $-1,20$ & 7,00 & 19 & 9,00 & 2,00 \\
\hline $\begin{array}{l}\text { Compra de equipamen- } \\
\text { tos }\end{array}$ & 9,48 & 6 & 8,80 & $-0,68$ & 10,00 & 8 & 10,00 & 0,00 \\
\hline $\begin{array}{l}\text { Abastecimento mediado } \\
\text { franqueador }\end{array}$ & 9,48 & 7 & 7,64 & $-1,84$ & 9,00 & 9 & 8,00 & $-1,00$ \\
\hline $\begin{array}{l}\text { Treinamento de admi- } \\
\text { nistração financeira }\end{array}$ & 9,44 & 8 & 7,28 & $-2,16$ & 8,00 & 18 & 8,00 & 0,00 \\
\hline $\begin{array}{l}\text { Treinamento de marke- } \\
\text { ting }\end{array}$ & 9,44 & 9 & 8,00 & $-1,44$ & 9,00 & 11 & 10,00 & 1,00 \\
\hline $\begin{array}{l}\text { Assistência em propa- } \\
\text { ganda }\end{array}$ & 9,44 & 10 & 7,72 & $-1,72$ & 8,00 & 17 & 9,00 & 1,00 \\
\hline Ponto comercial & 9,40 & 11 & 7,44 & $-1,96$ & 8,00 & 13 & 8,00 & 0,00 \\
\hline Contrato de franquia & 9,28 & 12 & 8,80 & $-0,48$ & 10,00 & 1 & 10,00 & 0,00 \\
\hline $\begin{array}{l}\text { Treina atendimento } \\
\text { cliente }\end{array}$ & 9,24 & 13 & 7,72 & $-1,52$ & 10,00 & 6 & 9,00 & $-1,00$ \\
\hline Material promocional & 9,24 & 14 & 8,08 & $-1,16$ & 10,00 & 5 & 9,00 & $-1,00$ \\
\hline $\begin{array}{l}\text { Treinamento de gestão } \\
\text { de operações }\end{array}$ & 9,20 & 15 & 8,08 & $-1,12$ & 8,00 & 15 & 9,00 & 1,00 \\
\hline $\begin{array}{l}\text { Layout unidade fran- } \\
\text { queada }\end{array}$ & 9,12 & 16 & 7,44 & $-1,68$ & 8,00 & 16 & 9,00 & 1,00 \\
\hline
\end{tabular}




\begin{tabular}{|c|c|c|c|c|c|c|c|c|}
\hline \multicolumn{9}{|c|}{ Perspectiva do franqueado do relacionamento de curto prazo prazoprazo } \\
\hline \multirow[t]{2}{*}{ Atributo } & \multicolumn{4}{|c|}{$\begin{array}{l}\text { Avaliação pelo Franqueado- } \\
\text { FFrFFrfranqueado* }\end{array}$} & \multicolumn{4}{|c|}{$\begin{array}{l}\text { Avaliação pelo Franqueador } \\
\text { Frafranqueador }^{\star \star}\end{array}$} \\
\hline & $\mathrm{E}$ & $\mathrm{R}$ & $\mathrm{D}$ & $\mathrm{L}^{\star}$ & $\mathrm{E}$ & $\mathrm{R}$ & $\mathrm{D}$ & $L^{\star \star}$ \\
\hline $\begin{array}{l}\text { Treinamento de recursos } \\
\text { humanos }\end{array}$ & 9,08 & 17 & 7,44 & $-1,64$ & 7,00 & 20 & 8,00 & 1,00 \\
\hline $\begin{array}{l}\text { Facilidade no financia- } \\
\text { mento }\end{array}$ & 8,92 & 18 & 8,08 & $-0,84$ & 9,00 & 10 & 9,00 & 0,00 \\
\hline $\begin{array}{l}\text { Abastecimento licencia- } \\
\text { do franqueador }\end{array}$ & 8,76 & 19 & 8,28 & $-0,48$ & 9,00 & 12 & 9,00 & 0,00 \\
\hline Inauguração & 8,72 & 20 & 7,40 & $-1,32$ & 10,00 & 7 & 9,00 & $-1,00$ \\
\hline $\begin{array}{l}\text { Fonte: os autores. } \\
\text { E - Média das expectativas } \\
\text { Lacunas }\end{array}$ & \multicolumn{4}{|c|}{$\mathrm{R}$ - Ranking das expectativas } & \multicolumn{3}{|c|}{ D - Desempenho } & $\mathrm{L}-$ \\
\hline
\end{tabular}

Os 20 atributos foram divididos em três grupos, de acordo com a expectativa (importância) conferida pelo franqueado. Tal estratificação foi realizada para organizar os atributos conforme a Matriz de Oportunidades, segundo Stock e Lambert (2001). Tal matriz é formada por nove áreas, as quais apresentam sugestões de ações, fruto do cruzamento dos três grupos de importância e dos três grupos de lacunas de qualidade do serviço. Os 20 atributos da perspectiva do franqueado no relacionamento de curto prazo foram agrupados da seguinte forma: mais importantes (primeiro ao sétimo do ranking de importância); medianamente importantes (oitavo a décimo terceiro no ranking de importância) e menos importantes (décimo quarto ao vigésimo do referido ranking).

Os atributos mais importantes podem ser considerados críticos na satisfação do franqueado no relacionamento com o seu franqueador. Se o franqueador deseja melhorar o relacionamento com o seu franqueado, necessita centrar seus recursos nesses atributos. Se por um lado, lacunas positivas nesses atributos podem fortalecer o relacionamento, por outro, lacunas negativas tendem a desgastá-lo. Seguindo a lógica da Matriz absoluta de Oportunidades proposta por Stock e Lambert (2001), atributos com grande importância, que apresentam profundas lacunas negativas, merecem, definitivamente, um cuidado especial por parte do franqueador. Atributos localizados entre os medianamente importantes e os menos importantes também devem ser trabalhados, porém, sem a mesma ênfase que os mais importantes. 
A expectativa dos atributos para o franqueado variou entre 8,72 e 9,88, o que significa altas expectativas para todos os atributos. Os mais valorizados foram: acesso ao franqueador $(9,88)$, consultoria de campo $(9,64)$, manual de operações $(9,56)$, análise da viabilidade de implantação da franquia $(9,52)$ e abastecimento no franqueador $(9,52)$. Por outro lado, os atributos menos importantes foram: apoio no desenvolvimento do layout da franquia $(9,12)$, treinamento em recursos humanos $(9,08)$, apoio para o financiamento da franquia em bancos $(8,92)$, abastecimento licenciado pelo franqueador $(8,76)$ e apoio na inauguração da franquia $(8,72)$.

A avaliação do desempenho do franqueador pelo franqueado apresentou altos valores, de 7,28 a 9,52, entretanto, como as notas conferidas para a importância foram ainda mais elevadas, há lacunas negativas de qualidade em todos os atributos dessa perspectiva. A lacuna mais profunda diz respeito ao treinamento quanto à administração financeira $(-2,16)$, seguida da análise da viabilidade da implantação da franquia $(-2,08)$, do apoio na seleção do ponto $(-1,96)$, do abastecimento mediado pelo franqueador $(-1,84)$ e apoio em propaganda $(-1,72)$. A Tabela 2 expõe as maiores e as menores lacunas, além do ranking de importância de acordo com a percepção do franqueado.

Tabela 2 - Maiores e menores lacunas de qualidade na percepção do franqueado em curto prazo

\begin{tabular}{|c|c|c|c|c|c|}
\hline \multicolumn{3}{|l|}{ Maiores lacunas } & \multicolumn{3}{|l|}{ Menores lacunas } \\
\hline Atributo & $\mathrm{L}$ & $\mathrm{R}$ & Atributo & $\mathrm{L}$ & $\mathrm{R}$ \\
\hline $\begin{array}{l}\text { Treinamento administração } \\
\text { financeira }\end{array}$ & $-2,16$ & 8 & $\begin{array}{l}\text { Abastecimento no franque- } \\
\text { ador }\end{array}$ & $-1,20$ & 5 \\
\hline Análise viabilidade & $-2,08$ & 4 & Material promocional & $-1,16$ & 14 \\
\hline Ponto comercial & $-1,96$ & 11 & $\begin{array}{l}\text { Treinamento de gestão de } \\
\text { operações }\end{array}$ & $-1,12$ & 15 \\
\hline $\begin{array}{l}\text { Abastecimento mediado } \\
\text { pelo franqueador }\end{array}$ & $-1,84$ & 7 & $\begin{array}{l}\text { Facilidade no financia- } \\
\text { mento }\end{array}$ & $-0,84$ & 18 \\
\hline Assistência em propaganda & $-1,72$ & 10 & Compra de equipamentos & $-0,68$ & 6 \\
\hline $\begin{array}{l}\text { Layout da unidade fran- } \\
\text { queada }\end{array}$ & $-1,68$ & 16 & Consultoria de campo & $-0,56$ & 2 \\
\hline $\begin{array}{l}\text { Treinamento de recursos } \\
\text { humanos }\end{array}$ & $-1,64$ & 17 & $\begin{array}{l}\text { Abastecimento licenciado } \\
\text { franqueador }\end{array}$ & $-0,48$ & 19 \\
\hline $\begin{array}{l}\text { Treinamento de atendi- } \\
\text { mento ao cliente }\end{array}$ & $-1,52$ & 13 & Contrato de franquia & $-0,48$ & 12 \\
\hline Treinamento de marketing & $-1,44$ & 9 & Acesso ao franqueador & $-0,36$ & 1 \\
\hline Inauguração & $-1,32$ & 20 & Manual de operações & $-0,24$ & 3 \\
\hline
\end{tabular}

Fonte: os autores. 
Merecem atenção especial do franqueador: análise da viabilidade, quarta do ranking de importância do franqueado, com a segunda maior lacuna negativa $(-2,08)$, e abastecimento mediado pelo franqueador, sétimo do ranking de importância do franqueado, com a quarta lacuna negativa mais profunda $(-1,84)$.

Aavaliação do franqueador sobre a importância conferida pelo seu franqueado a cada atributo variou de 7 a 10, sendo essa a resposta mais frequente. Como os representantes do franqueador preencheram em conjunto apenas um questionário para conceber a percepção do franqueador, houve empate na importância conferida para alguns atributos. Diante disso, o próprio franqueador ordenou tais atributos de forma que o primeiro do ranking é o mais importante e o último, o de menor importância.

É desejável que expectativas de franqueado e franqueador se mostrem alinhadas. O coeficiente de Spearman foi utilizado para medir o grau de correlação entre as ordenações (rankings) estabelecidas por franqueado e franqueador. Aqui, a comparação ocorre entre o nível de expectativa do franqueado e o grau de expectativa que o franqueador pensa que o franqueado confere aos atributos. Isso permite compreender em qual medida o franqueador dessa rede conhece a expectativa do seu franqueado quanto aos atributos da perspectiva do franqueado (curto prazo). $\mathrm{O}$ teste revelou um baixo alinhamento entre as necessidades do franqueado e o que o franqueador pensa ser a necessidade daquele, tendo sido obtido o resultado 0,241 para um nível de significância de 95\%.

$\mathrm{Na}$ autoavaliação de desempenho, o franqueador conferiu a si mesmo notas que variaram de 8 a 10. Em quatro atributos, o franqueador reconhece que oferece serviços abaixo da expectativa do seu franqueado, são eles: desenvolvimento de material promocional, treinamento no atendimento ao cliente, apoio na inauguração e abastecimento mediado pelo franqueador. Apesar de o franqueado apontar lacunas negativas de qualidade em todos os atributos do relacionamento de curto prazo, o franqueador entende que oferece serviços acima das expectativas do seu franqueado em seis atributos, representados por lacunas positivas de qualidade, discriminadas a seguir com as lacunas entre parênteses: treinamento quanto ao marketing $(+1)$, manual de operações $(+1)$, apoio no desenvolvimento do layout da franquia $(+1)$, apoio em propaganda $(+1)$, treinamento em recursos humanos $(+1)$ e abastecimento no franqueador $(+2)$. 


\section{2 PERSPECTIVA DO FRANQUEADOR DO RELACIONAMENTO DE CURTO PRAZO}

A Tabela 3 representa as percepções do franqueador e do franqueado acerca dos 12 atributos da perspectiva do franqueador do relacionamento de curto prazo. Para cada parte envolvida no relacionamento estão expostos: expectativa $(\mathrm{E})$, ranking (R) em que o primeiro é o atributo mais importante e o último, o menos importante, desempenho (D) e lacuna da qualidade (L).

Tabela 3 - Percepções do franqueador e do franqueado da perspectiva do franqueador em curto prazo

\begin{tabular}{|c|c|c|c|c|c|c|c|c|}
\hline \multicolumn{9}{|c|}{ Perspectiva do franqueador do relacionamento de curto prazo } \\
\hline \multirow{2}{*}{ Atributo } & \multicolumn{4}{|c|}{ Avaliação pelo franqueador ${ }^{\star}$} & \multicolumn{4}{|c|}{ Avaliação pelo franqueado ${ }^{\star \star}$} \\
\hline & $\mathrm{E}$ & $\mathrm{R}$ & $\mathrm{D}$ & $\mathrm{L}$ & $\mathrm{E}$ & $\mathrm{R}$ & $\mathrm{D}$ & $\mathrm{L}$ \\
\hline $\begin{array}{l}\text { Produtos e serviços autori- } \\
\text { zados }\end{array}$ & 10,00 & 1 & 10,00 & 0,00 & 9,28 & 6 & 9,64 & 0,36 \\
\hline Taxa de royalties & 10,00 & 2 & 8,20 & $-1,80$ & 9,72 & 3 & 8,72 & $-1,00$ \\
\hline Transparência em auditoria & 10,00 & 3 & 9,00 & $-1,00$ & 9,88 & 1 & 9,88 & 0,00 \\
\hline Taxa da franquia & 10,00 & 4 & 9,92 & $-0,08$ & 9,72 & 2 & 9,60 & $-0,12$ \\
\hline Identidade visual & 10,00 & 5 & 9,00 & $-1,00$ & 9,20 & 8 & 9,52 & 0,32 \\
\hline Território & 10,00 & 6 & 10,00 & 0,00 & 9,72 & 4 & 9,88 & 0,16 \\
\hline $\begin{array}{l}\text { Cumpre treinamento de } \\
\text { atendimento ao cliente }\end{array}$ & 10,00 & 7 & 8,16 & $-1,84$ & 9,24 & 7 & 9,04 & $-0,20$ \\
\hline $\begin{array}{l}\text { Cumpre treinamento ma- } \\
\text { rketing }\end{array}$ & 10,00 & 8 & 7,60 & $-2,40$ & 8,76 & 12 & 8,76 & 0,00 \\
\hline $\begin{array}{l}\text { Cumpre treinamento admini- } \\
\text { tração financeira }\end{array}$ & 10,00 & 9 & 8,08 & $-1,92$ & 8,96 & 10 & 8,20 & $-0,76$ \\
\hline $\begin{array}{l}\text { Cumpre treinamento de } \\
\text { recursos humanos }\end{array}$ & 10,00 & 10 & 8,08 & $-1,92$ & 8,76 & 11 & 8,24 & $-0,52$ \\
\hline Cumpre missão & 9,00 & 11 & 10,00 & 1,00 & 9,52 & 5 & 9,40 & $-0,12$ \\
\hline $\begin{array}{l}\text { Cumpre treinamento de } \\
\text { gestão operações }\end{array}$ & 9,00 & 12 & 8,32 & $-0,68$ & 9,04 & 9 & 8,48 & $-0,56$ \\
\hline
\end{tabular}

Fonte: os autores.

E-Média das expectativas $\quad \mathbf{R}$-Ranking das expectativas $\quad$ D - Desempenho $\quad$ L-Lacunas * Avaliação pelos módulos XI e XII. * Avaliação pelos módulos V e VI - expectativas que o franqueado pensa ser do franqueador e autoavaliação do desempenho do franqueado. 
Os 12 atributos estão classificados em três níveis, de acordo com a expectativa (importância) conferida pelo franqueador: mais importantes (primeiro ao quarto do ranking de importância); medianamente importantes (quinto ao oitavo no ranking de importância) e menos importantes (nono ao décimo segundo do mesmo ranking). Nesse ponto, as colocações a respeito da satisfação com os serviços no relacionamento de curto prazo mudam de sentido, isto é, anteriormente, na perspectiva do franqueado, o prestador de serviços era o franqueador. Agora, na perspectiva do franqueador, é o franqueado. Portanto, caso o franqueado queira melhorar o relacionamento, carece situar seus esforços principalmente nos atributos mais valorizados pelo seu franqueador.

A importância dos atributos para o franqueador oscilou somente entre $9 \mathrm{e}$ 10. As notas repetidas dificultam a construção de um ranking de importância. Diante dessa situação, o próprio franqueador ordenou os atributos, sendo o primeiro do ranking o mais importante e o último, o de menor importância. Os quatro atributos mais valorizados pelo franqueador dessa rede foram: oferta de produtos e serviços autorizados pelo franqueador (10), pagamento de royalties (10), transparência em auditorias (10) e pagamento da taxa de franquia (10). Os quatro menos valorizados foram: cumprimento do treinamento em marketing (10), cumprimento do treinamento em administração financeira (10), cumprimento da missão (9) e cumprimento do treinamento em gestão de operações (9).

A avaliação do franqueado sobre o que pensa ser importante para o seu franqueador variou entre 8,76 e 9,88. De acordo com o franqueado, os atributos mais importantes para o franqueador são: transparência em auditorias $(9,88)$, pagamento da taxa de franquia $(9,72)$, pagamento dos royalties $(9,72)$ e atuação apenas em território acordado com o franqueador $(9,72)$.

O teste de Spearman revelou 0,615 (significância de 95\%) de correlação entre os rankings de importância estabelecidos por franqueador e franqueado. Esse número sugere uma sintonia mediana entre expectativas de franqueador e franqueado para os atributos da perspectiva do franqueador na projeção de curto prazo. Indica ainda, que o franqueado conhece razoavelmente o que o seu franqueador espera nos aspectos ligados ao início da operação da franquia.

Ao avaliar o desempenho do seu franqueado, o franqueador aponta lacunas negativas da qualidade em nove de 12 atributos. Não houve lacunas para a oferta de produtos e serviços autorizados pelo franqueador e a atuação em território acordado com o franqueador. Quanto ao cumprimento da missão, a lacuna foi positiva. A 
Tabela 4 apresenta as maiores e menores lacunas, bem com o ranking de importância de acordo com a percepção do franqueador.

Tabela 4 - Maiores e menores lacunas de qualidade na percepção do franqueador em curto prazo.

\begin{tabular}{|c|c|c|c|c|c|}
\hline \multicolumn{3}{|l|}{ Maiores lacunas } & \multicolumn{3}{|l|}{ Menores lacunas } \\
\hline Atributo & $\mathrm{L}$ & $\mathrm{R}$ & Atributo & $\mathrm{L}$ & $\mathrm{R}$ \\
\hline $\begin{array}{l}\text { Cumpre treinamento de } \\
\text { marketing }\end{array}$ & $-2,40$ & 8 & Identidade visual & $-1,00$ & 5 \\
\hline $\begin{array}{l}\text { Cumpre treinamento } \\
\text { administração financeira }\end{array}$ & $-1,92$ & 9 & $\begin{array}{l}\text { Cumpre treinamento de } \\
\text { gestão operações }\end{array}$ & $-0,68$ & 12 \\
\hline $\begin{array}{l}\text { Cumpre treinamento } \\
\text { recursos humanos }\end{array}$ & $-1,92$ & 10 & Taxa da franquia & $-0,08$ & 4 \\
\hline $\begin{array}{l}\text { Cumpre treinamento } \\
\text { atendimento ao cliente }\end{array}$ & $-1,84$ & 7 & $\begin{array}{l}\text { Produtos e serviços auto- } \\
\text { rizados }\end{array}$ & 0,00 & 1 \\
\hline Taxa de royalties & $-1,80$ & 2 & Território & 0,00 & 6 \\
\hline $\begin{array}{l}\text { Transparência em audi- } \\
\text { toria }\end{array}$ & $-1,00$ & 3 & Cumpre missão & 1,00 & 11 \\
\hline
\end{tabular}

$\mathrm{Na}$ avaliação do franqueador, as quatro lacunas negativas mais expressivas recaíram sobre atributos que não estão entre os mais importantes: cumprimento do treinamento de marketing $(-2,4)$, cumprimento do treinamento de administração financeira $(-1,92)$ e cumprimento do treinamento de recursos humanos $(-1,92)$. No entanto, o pagamento da taxa de royalties, segundo no ranking de importância, aparece com uma lacuna significativa $(-1,8)$.

O franqueado reconhece que o seu desempenho deixa a desejar no atributo pagamento da taxa de royalties, sendo esta a maior lacuna (-1) na sua própria percepção. Entretanto, não reconhece lacunas de qualidade na transparência em auditorias. E mais, no que se refere ao respeito à identidade visual da franquia, entende que o seu desempenho é superior às expectativas do franqueador.

\section{3 PERSPECTIVAS DO FRANQUEADOR E DO FRANQUEADO DO RELACIONAMENTO DE LONGO PRAZO}

A Tabela 5 representa as percepções do franqueador e do franqueado quanto aos sete atributos da projeção de longo prazo, que é comum aos dois. Para o franqueador e o franqueado estão expostos: expectativa $(\mathrm{E})$, ranking $(\mathrm{R})$, em que o 
primeiro é o atributo mais importante e o último o menos importante, desempenho (D) e lacuna da qualidade (L).

Assim como na projeção de curto prazo, os sete atributos da projeção de longo prazo estão divididos em três grupos de acordo com sua importância segundo as expectativas do franqueador e do franqueado: mais importantes (primeiro e segundo dos rankings), medianamente importantes (terceiro ao quinto dos rankings de importância) e menos importantes (sexto e sétimo dos rankings). As notas de importância para o franqueador oscilaram somente entre 9 e 10, por isso o próprio franqueador ordenou os atributos, sendo o primeiro do ranking o mais importante e o último, o de menor importância.

Tabela 5 - Percepções do franqueador e do franqueado no relacionamento de longo prazo

Perspectivas do franqueador e do franqueado no relacionamento de curto prazo

\begin{tabular}{|c|c|c|c|c|c|c|c|c|}
\hline \multirow{2}{*}{ Atributo } & \multicolumn{4}{|c|}{ Avaliação pelo franqueador ${ }^{\star}$} & \multicolumn{4}{|c|}{ Avaliação pelo franqueado ${ }^{\star \star}$} \\
\hline & $\mathrm{E}$ & $\mathrm{R}$ & $\mathrm{D}$ & $\mathrm{L}$ & $\mathrm{E}$ & $\mathrm{R}$ & $\mathrm{D}$ & $\mathrm{L}$ \\
\hline Competência & 10,00 & 1 & 8,28 & $-1,72$ & 9,88 & 1 & 9,72 & $-0,16$ \\
\hline Honestidade & 10,00 & 2 & 8,68 & $-1,32$ & 9,88 & 2 & 9,84 & $-0,04$ \\
\hline Solidariedade & 10,00 & 3 & 8,92 & $-1,08$ & 9,80 & 3 & 9,64 & $-0,16$ \\
\hline Mutualidade & 10,00 & 4 & 8,96 & $-1,04$ & 9,60 & 4 & 8,92 & $-0,68$ \\
\hline Compromisso & 9,00 & 5 & 9,00 & 0,00 & 9,56 & 5 & 9,00 & $-0,56$ \\
\hline $\begin{array}{l}\text { Harmonização } \\
\text { de conflitos }\end{array}$ & 10,00 & 6 & 9,00 & $-1,00$ & 9,52 & 6 & 9,60 & 0,08 \\
\hline Flexibilidade & 9,00 & 7 & 8,88 & $-0,12$ & 9,32 & 7 & 8,76 & $-0,56$ \\
\hline
\end{tabular}

Fonte: os autores.

$\mathbf{E}$ - Média das expectativas $\quad \mathbf{R}$ - Ranking das expectativas $\quad \mathbf{D}$ - Desempenho $\quad \mathbf{L}$ - Lacunas *Avaliação pelos módulos IX e X. $\quad$ ** Avaliação pelos módulos III e IV.

Vale destacar a perfeita sintonia entre as partes envolvidas no relacionamento quanto aos atributos da projeção de longo prazo. O teste de Spearman apontou a correlação máxima (1). Competência e honestidade, ambos componentes da confiança, segundo Dickey, Mcknight e George (2008), são os atributos mais valorizados. Por sua vez, harmonização de conflitos e flexibilidade são os menos importantes. 
Ao avaliar o franqueado, o franqueador aponta lacunas negativas de qualidade em seis atributos que variam de $-1,72$ a $-0,12$. Por sua vez, ao avaliar o franqueador, o franqueado também assinala lacunas negativas da qualidade em seis atributos, mas com lacunas negativas mais rasas que oscilam entre -0,68 e -0,04. Apesar de a quantidade de lacunas negativas ser a mesma nas percepções do franqueador e do franqueado ao avaliarem o seu parceiro de franchising, a profundidade dessas lacunas difere significativamente. No mais, as quatro lacunas negativas com maior expressão apontadas pelo franqueador ao avaliar seu franqueado são justamente nos atributos mais importantes. Isso não acontece no sentido inverso, uma vez que nos atributos mais valorizados pelo franqueado são registradas as menores lacunas negativas para a qualidade do franqueador.

\section{CONSIDERAÇÕES FINAIS}

O modelo desenvolvido se mostrou adequado na avaliação da qualidade do relacionamento franqueador-franqueado em uma rede de franquias do setor Farmacêutico. Tanto na perspectiva do franqueado quanto na do franqueador, em curto e longo prazos, os atributos receberam altas notas de importância (expectativas), o que reforça a escolha adequada dos atributos selecionados nas literaturas nacional e internacional sobre of franchising.

É desejável que as expectativas do franqueador e do franqueado estejam alinhadas no relacionamento de curto e longo prazos. Parte-se do princípio que lacunas de qualidade, positivas ou negativas, afetam o relacionamento entre franqueador e franqueado. Um bom relacionamento pressupõe a ausência de lacunas negativas significativas, especialmente em atributos de grande importância. Grandes lacunas negativas de qualidade tendem a corroer os relacionamentos, tornando-os precários. Por outro lado, lacunas positivas, sobretudo em atributos muito valorizados, fortalecem o relacionamento.

Em princípio, o franqueador possui mais estrutura, experiência e informações que o franqueado. Foi o franqueador que selecionou o franqueado para fazer parte da rede de franquias; é de se esperar que conheça bem as necessidades deste. No entanto, no caso em tela, os resultados sugerem que o franqueado conhece melhor as expectativas do franqueador do que este conhece as expectativas do franqueado. Isso abre a possibilidade de o franqueador investir seus recursos em atributos pouco valorizados pelo franqueado. Essa pode ser a razão pela qual o franqueado, ao avaliar 
o franqueador, tenha apontado lacunas negativas de qualidade em todos os atributos de curto prazo. Apesar disso, o franqueador somente reconhece suas limitações em quatro desses atributos.

Franqueador e franqueados demonstraram que suas prioridades estão alinhadas nos sete atributos que compõem o relacionamento de longo prazo. Isso significa uma clareza no que franqueados e franqueador esperam do seu relacionamento. $\mathrm{Na}$ avaliação do franqueador, o franqueado fica aquém das expectativas em seis de sete atributos. As maiores lacunas de qualidade do franqueado se localizam justamente nos atributos mais valorizados pelo franqueador (competência, honestidade, solidariedade e mutualidade). Por outro lado, o franqueado também percebe lacunas de qualidade em seis dos sete atributos da projeção de longo prazo, porém, o franqueador apresenta, na percepção do franqueado, menores lacunas de qualidade nos atributos mais valorizados. As lacunas negativas de qualidade apontadas pelo franqueado são menores que aquelas apontadas pelo franqueador na maioria dos atributos.

Cabe apontar que o modelo das lacunas de qualidade se mostrou claramente oportuno e aderente ao processo de avaliação do relacionamento entre franqueados e franqueador em curto e longo prazos em uma rede de franquias do setor Farmacêutico. Não se pode deixar de apontar que a concepção de Gronross (2009) sobre as lacunas de percepção entre empresas e seus clientes se encaixa adequadamente nas relações interempresariais de uma rede de franquias.

Para a ciência administrativa, o modelo proposto contribui por enxergar a relação franqueador-franqueado por meio de um novo ângulo: das lacunas da qualidade do serviço. Por sua vez, colabora para que franqueador e franqueados compreendam os pontos-chave para o fortalecimento da relação entre ambos e, consequentemente, para beneficiar o desempenho da rede. Entretanto, o modelo carece ser testado em outros segmentos, como acessórios pessoais, alimentação e vestuário. Dessa forma, sugere-se que o modelo proposto seja aplicado em diversos setores e países, a fim de ser aperfeiçoado e contemplar as particularidades dos diversos negócios e culturas.

\section{REFERÊNCIAS}

ABDULLAH, F. et al. Measuring and managing franchisee satisfaction: a study of academic franchising. Journal of Modelling in Management, v. 3, n. 2, p. 182199, 2008. 
ASSOCIAÇÃO BRASILEIRA DE FRANCHISING. Evolução do setor 20032014. Disponível em: < http://www.portaldofranchising.com.br/numeros-dofranchising/evolucao-do-setor-2003-2014> . Acesso em: 19 abr. 2015.

BORDONABA-JUSTE, M. V.; POLO-REDONDO, Y. Differences between short and long-term relationships: an empirical analysis in franchise systems. Journal of Strategic Marketing, v. 16, n. 4, p. 327-354, 2008.

BOWERSOX, D.; CLOSS, D.; COOPER, M. B. Gestão Logística de Cadeias de Suprimentos. São Paulo: Bookman, 2006.

BRITO, E. P. Z.; VIEIRA, V. A.; ESPARTEL, L. B. A pesquisa na área do varejo: reflexões e provocações. Revista de Administração Contemporânea, v. 51, n. 6, p. 522-527, 2011.

COHEN, M.; SILVA, J. F. O Impacto das decisões estratégicas no desempenho dos franqueados em fast-food: o papel do relacionamento franqueador-franqueado. Revista de Administração Contemporânea, v. 4, n. 1, p. 109-131, 2000.

CORRÊA, H. L.; CAON, M. Gestão de Serviços: lucratividade por meio de operações e de satisfação dos clientes. São Paulo: Atlas, 2002.

DANTAS, M. L. R. et al. Satisfação e desempenho na interface franqueadorfranqueado: um estudo de caso em farmácias de manipulação. In: ENCONTRO NACIONAL DE ENGENHARIA DE PRODUÇÃO, 26., 2012, Bento Gonçalves. Anais... Bento Gonçalves: ABEPRO, 2012.

DANT, R. P.; LI, Z. G.; WORTZEL, L. H. Linking relationship quality and service quality in franchise systems: model e measurement. Journal of Marketing Channels, v. 4, n. 1, p. 103-124, 1995.

DAVIDOVITSCH, L.; CALDAS, L. F.; SILVA, J. F. Estruturação das redes de fastfood: um estudo empírico sobre os antecedentes do franchising e suas implicações sobre o desempenho das firmas. Revista de Administração, v. 44, n. 4, p. 299-312, 2009.

DAVIES, M. A. P. et al. A model of trust and compliance in franchise relationships. Journal of Business Venturing, v. 26, p. 321-340, 2011.

DICKEY, M.; MCKNIGHT, D.; GEORGE, F. The role of trust in franchise organizations. International Journal of Organizational Analysis, v. 15, n. 3, p. 251-282, 2008. 
ESPINHA, P. G.; MACHADO, H. P. V.; RODRIGUES, R. M. I. Considerações sobre o empreendedorismo e a exploração de negócios no franchising. In: ENCONTRO DE ESTUDOS SOBRE EMPREENDEDORISMO E GESTÃO DE PEQUENAS EMPRESAS, 4., 2005, Curitiba. Anais... Curitiba, 2005.

GRONROSS, C. Marketing: gerenciamento e serviços. 3. ed. Rio de Janeiro: Elsevier, 2009.

GRUNHAGEN, M.; DORSCH, M. J. Does the franchisor provide value to franchisees? Past, current, and future value assessments of two franchisee types. Journal of Small Business Management, Florida, v. 41, n. 4, p. 366-384, 2003.

LOVELOCK, C.; WRIGHT, L. Serviços: marketing e gestão. São Paulo: Saraiva, 2006.

MAEMURA, M. M. D. Análise de conflitos e soluções adotadas por franquias do setor alimentício: um estudo multicaso. 2009. Dissertação (Mestrado em Administração de Organizações)-Universidade de São Paulo, Ribeirão Preto, 2009.

MCDONELL, J.; BEATSON, A.; HUANG, C. Investigating relationships between relationship quality, customer loyalty and cooperation: an empirical study of convenience stores franchise chain systems. Asia Pacific Journal of Marketing and Logistics, v. 23, n. 3, p. 367-385, 2011.

MELO, P. L. R.; ANDREASSI, T. Publicação científica nacional e internacional sobre franchising: levantamento e análise do período 1998-2007. Revista de Administração Contemporânea, v. 14, n. 2, p. 268-288, 2010.

MONROY, M. F.; ALZOLA, L. M. An analyses of quality management in franchise systems. European Journal of Marketing, v. 39, n. 5-6, p. 585-605, 2005.

PAIVA, P. A. S. B. Relacionamento entre franchisador e franchisado: caso de estudo: Casas do Benfica. 2009. 109 p. Dissertação (Mestrado em Engenharia e Gestão Industrial)-Universidade Técnica de Lisboa, Portugal, 2009.

PARASURAMAN, A.; ZEITHAML, V. A.; BERRY, L. L. A conceptual model of service quality and its implications for future research. Journal of Marketing, $v$. 49, p. 41-50, 1985.

PARASURAMAN, A.; ZEITHAML, V. A.; BERRY, L. L. Um modelo conceitual de qualidade de serviço e suas implicações para pesquisa no futuro. Revista de Administração de Empresas, v. 46, n. 4, p. 96-106, 2006. 
PERRIGOT, R. Services vs retail chains: are there any differences?: Evidence from de French franchising industry. International Journal of Retail \& Distribution Management, v. 34, n. 12, p. 918-930, 2006.

PRADO, M. N. Franchising na alegria e na tristeza. São Paulo: Lamônica, 2008.

ROCHA, F. B. Impacto da postura comportamental do franqueado e de sua relação com o franqueador no desempenho da franquia. Dissertação (Mestrado em Administração)-Pontifícia Universidade Católica do Paraná, Curitiba, 2010.

SILVA, V.; AZEVEDO, P. Formas plurais no franchising de alimentos: evidências de estudos de caso na França e no Brasil. Revista de Administração Contemporânea, v. 11, 2007.

SILVA, V.; AZEVEDO, P. (Org.). Teoria e Prática do Franchising: Estratégia e organização de redes de franquias. São Paulo: Atlas, 2012. 242 p.

SPINELLI, S.; BIRLEY, S. Toward a theory of conflict in the franchise system. Journal of Business Venturing, Oxford, v. 11, n. 5, p. 329-342, 1996.

STOCK, J. R.; LAMBERT, D. M. Strategic logistics management. 4. ed. New York: McGraw-Hill, 2001.

VANCE, P. S.; FÁVERO, L. P. L.; LUPPE, M. R. Franquia empresarial: um estudo das características do relacionamento entre franqueadores e franqueados no Brasil. Revista de Administração, v. 43, n. 1, 2008.

VIEIRA, V. A.; SLONGO, L. A. Marketing de relacionamento entre franqueador e franqueado: proposta de dois modelos. Revista Alcance, v. 13, n. 3, p. 311-328, 2006.

WRIGHT, O.; GRACE, A. Trust and commitment within franchise systems: an Australian and New Zeland perspective. Asia Pacific Journal of Marketing Logistics, v. 23, n. 4, p. 486-500, 2011.

ZEITHAML, V. A.; BITNER, M. J. Marketing de Serviços: a empresa com foco no cliente. 2. ed. São Paulo: Bookman, 2003. 


\section{Como citar este artigo:}

DANTAS, Marcel Lima Ribeiro et al. Um modelo de avaliação do relacionamento Z franqueador-franqueado com base nas lacunas da qualidade do serviço: um estudo 穵 de caso em uma rede do setor farmacêutico. RACE, Revista de Administração, Contabilidade e Economia. Joaçaba: Ed. Unoesc, v. 14, n. 2, 677-706, maio/ago. 2015. Disponível em: < http://editora.unoesc.br/index.php/race>. Acesso em: dia/ mês/ano.

Dantas, M. L. R., Campos, D. F., Pereira Filho E., \& Veiga Neto, A. R. Um $\llbracket$ modelo de avaliação do relacionamento franqueador-fraqueado com base nas

\& lacunas da qualidade do serviço: um estudo de caso em uma rede do setor Farmacêutico. RACE, Revista de Administração, Contabilidade e Economia, 14(2), 677706. Recuperado em dia/mês/ano, de http://editora.unoesc.br/index.php/race. 
